\title{
Modelling the effects of variable viscosity in unsteady flow of nanofluids in a pipe with permeable wall and convective cooling
}

\author{
Sara Khamis ${ }^{1}$, Oluwole Daniel Makinde ${ }^{2}$, Yaw Nkansah-Gyekye ${ }^{1}$ \\ ${ }^{1}$ Nelson Mandela African Institution of Science and Technology (NM-AIST), P. O. Box 447, Arusha, Tanzania \\ ${ }^{2}$ Faculty of Military Science, Stellenbosch University, Private Bag X2, Saldanha 7395, South Africa
}

Email address:

khamiss@nm-aist.ac.tz (S. Khamis), makinded@gmail.com (O. D. Makinde), yaw.nkansah-gyekye@nm-aist.ac.tz (Y. Nkansah-Gyekye)

\section{To cite this article:}

Sara Khamis, Oluwole Daniel Makinde, Yaw Nkansah-Gyekye. Modelling the Effects of Variable Viscosity in Unsteady Flow of Nanofluids in a Pipe with Permeable Wall and Convective Cooling. Applied and Computational Mathematics.

Vol. 3, No. 3, 2014, pp. 75-84. doi: 10.11648/j.acm.20140303.12

\begin{abstract}
In this paper, the combined effects of variable viscosity, Brownian motion, thermophoresis and convective cooling on unsteady flow of nanofluids in a pipe with permeable wall are investigated. It is assumed that the pipe surface exchange heat with the ambient following the Newton's law of cooling. Using a semi discretization finite difference method coupled with Runge-Kutta Fehlberg integration scheme, the nonlinear governing equations of momentum and energy balance, and the equation for nanoparticles concentration are tackled numerically. Useful results for the velocity, temperature, nanoparticles concentration profiles, skin friction and Nusselt number are obtained graphically and discussed quantitatively.
\end{abstract}

Keywords: Porous Pipe Flow, Variable Viscosity, Nanofluids, Heat Transfer, Convective Cooling

\section{Introduction}

Some of the classical challenges facing fluid mechanics which have received much attention in several industrial and engineering processes are the problems of heat transfer and fluid flow embedded in geometries with permeable walls. Some examples include problems dealing with purification and filtration processes, transpiration cooling where the walls of a pipe containing heated fluid are protected from overheating by passing cooler fluid over the exterior surface of the pipe, petroleum technology, isotopes separation of Uranium-235 and Uranium-238 by gaseous diffusion for production of fuel used in nuclear reactor, controlling boundary layer flow over aircraft wings by injection or suction of fluid out of or into the wing, lubrication of porous bearings, ground water hydrology, leakage of water in river beds, methods of reducing rates of heat transfer in combustion chambers exhaust nozzles and porous walled flow reactors see [14]. Several studies have been done to focus this area. Karode [1] conducted a study on laminar flow in a channel with porous wall. He presented an analytical solution for the pressure drop in fluid flow in a rectangular slit and cylindrical tube for the case of constant wall permeability. Oxarango et al. [2] proposed one-dimensional model to investigate the heat transfer in laminar flow of a fluid in a channel with suction/injection wall. An analytic solution describing 2D steady laminar flow over an array of porous pipes for the case of low Reynolds number was presented by Moussy and Snider [3]. Several other researchers have done similar studies on heat transfer problems between two permeable parallel walls under different physical situations [4-7].

Convectional heat transfer in fluids such as water, mineral oil and ethylene glycol are widely used for heat exchange purposes in the industries and building application. However, conventional fluids remain penalized by their limited thermal properties among which are their low thermal conductivity. An innovative way of improving the heat transfer of these fluids is to suspend small amounts of nanometer sized (10-50 $\mathrm{nm})$ particles and fibers in the convective fluids. This new kind of fluid has attracted the interest of many researchers due to its thermal enhancement property. Nanofluids have enhanced thermophysical properties such as thermal conductivity, thermal diffusivity, viscosity and convective heat transfer coefficients compared with base fluids [8]. Among the important features of nanoparticles suspended in convectional fluids are Brownian motion and thermophoresis [9]. Brownian motion describes the random movement of 
nanoparticles in the base fluid. This random movement is due to collision of particles into each other. The collision passes on the kinetic energy of the particles to the molecules. Thermophoresis describes the nanoparticles dispersion in the base fluid due to temperature gradient.

Several researches have been conducted to analyze heat and mass transfer in nanofluids flow problems between two permeable walls under different physical situations. Mutuku-Njane and Makinde [11] performed a numerical analysis to investigate the combined effects on buoyancy and magnetic on a steady two-dimensional boundary layer flow of an electrically conducting water-based nanofluid containing three different types of nanoparticles: copper, aluminium oxide, and titanium dioxide past a convectively heated porous vertical plate with variable suction. Olanrewaju and Makinde [12] formulated a problem on the boundary layer stagnation point flow of a nanofluid over a permeable flat surface with Newtonian heating. The combined effects of viscous dissipation and Newtonian heating on boundary-layer flow over a flat plate for three types of water-based nanofluids containing metallic or nonmetallic for a range of nanoparticle volume fractions was investigated by Makinde [13]. He found that the heat transfer rate at the plate surface increases with increasing nanoparticle volume fraction and Biot number, while it decreases with the Brinkmann number. Recently, heat transfer characteristics of a Berman flow of water based nanofluids containing copper and alumina in a porous channel with Navier slip, viscous dissipation, and convective cooling was reported by Makinde et al. [14].

Moreover, many researchers studied the effects of temperature dependent viscosity in a nanofluid flow and heat transfer taking into account thermophoresis and Brownian motion. Makinde [18] has presented a work that examines the effect of thermal radiation on inherent irreversibility in the flow of a variable viscosity optically thin fluid through a channel with isothermal walls. Kuppalapalle et al. [19] carried out a numerical study to investigate the effects of the temperature dependent viscosity on the flow and heat transfer of a nanofluid over a flat surface in the presence of viscous dissipation. Furthermore, the effect of variable viscosity on thermal boundary layer over a permeable flat plate with radiation and convective surface boundary condition was reported by Makinde [20]. However, in all studies the effects of variable viscosity in unsteady flow of nanofluids in a pipe with permeable wall and convective cooling have not been investigated.

Therefore, the present study aimed to investigate the combined effects of variable viscosity, Brownian motion, thermophoresis and convective cooling on unsteady flow of nanofluids in a pipe with permeable wall. In the subsequent sections 2 and 3 the details of the model formulation together with the numerical solution techniques employed to tackle the problem are presented. In section 4, pertinent results are displayed graphically and discussed. Finally, conclusions are drawn in section 5 .

\section{Mathematical Model}

Consider the unsteady laminar flow of a water base incompressible variable viscosity nanofluids through a cylindrical pipe with permeable wall under the action of a constant axial pressure gradient. It is assumed that $V(>0)$ corresponds to uniform suction velocity at the pipe surface while $\mathrm{V}(<0)$ represents fluid injection into the pipe and the pipe surface exchange heat with the ambient surrounding following Newton's law of cooling as depicted in Figure 1 below:

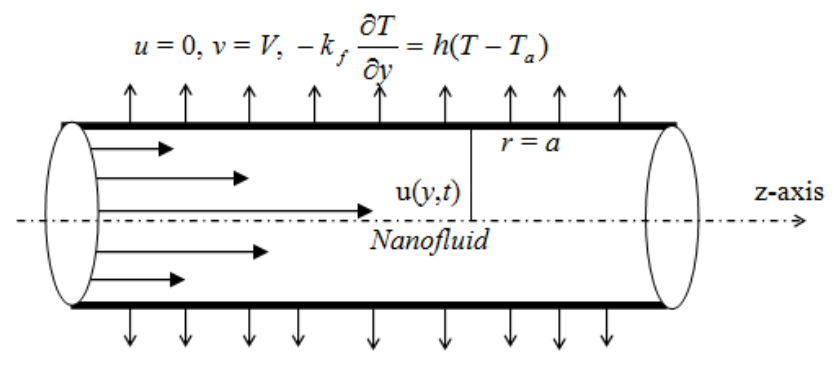

Figure 1. Schematic diagram of the problem

Using the Buongiorno nanofluid model [10] with the Brownian motion and thermophoresis effects, the governing equations for continuity, momentum, energy, and nanoparticles concentration are:

$$
\begin{gathered}
\frac{\partial u}{\partial z}=0 \\
\rho_{f}\left(\frac{\partial u}{\partial \bar{t}}+V \frac{\partial u}{\partial r}\right)=-\frac{\partial P}{\partial z}+\frac{1}{r} \frac{\partial}{\partial r}\left(r \mu_{f}(T) \frac{\partial u}{\partial r}\right) \\
\frac{\partial T}{\partial \bar{t}}+V \frac{\partial T}{\partial r}=\alpha_{f} \frac{1}{r} \frac{\partial}{\partial r}\left(r \frac{\partial T}{\partial r}\right)+ \\
\tau\left\{D_{B} \frac{\partial T}{\partial r} \frac{\partial \varphi}{\partial r}+\frac{D_{T}}{T_{a}}\left(\frac{\partial T}{\partial r}\right)^{2}\right\}+\frac{\alpha_{f} \mu_{f}(T)}{k_{f}}\left(\frac{\partial u}{\partial r}\right)^{2} \\
\frac{\partial \varphi}{\partial \bar{t}}+V \frac{\partial \varphi}{\partial r}=\frac{D_{B}}{r} \frac{\partial}{\partial r}\left(r \frac{\partial \varphi}{\partial r}\right)+\left(\frac{D_{T}}{T_{a}}\right)\left(\frac{\partial^{2} T}{\partial r^{2}}\right)
\end{gathered}
$$

where $D_{B}$ and $D_{T}$ are the Brownian and thermophoretic diffusion coefficients respectively, $u$ is the nanofluid velocity in the $z$-direction, $r$ is the radial distance, $a$ is the pipe radius, $T$ is the nanofluid temperature, $P$ is the nanofluid pressure, $\bar{t}$ is the time, $T_{a}$ is the ambient temperature which also corresponds to the nanofluid initial temperature, $\varphi$ is the concentration of nanoparticles, $\rho_{f}$ is the nanofluid density, $\alpha_{f}$ is the thermal diffusivity of the nanofluid, and $\tau$ is the ratio of solid particles heat capacitance to that of the nanofluid heat capacitance. The dynamic viscosity of nanofluid is assumed to be temperature dependent which can be expressed as [7, 22];

$$
\mu_{f}(T)=\mu_{0} e^{-m\left(T-T_{a}\right)}
$$


where $\mu_{0}$ is the nanofluid viscosity at the ambient temperature $T_{a}$ and $m$ is the variable viscosity parameter. The initial and boundary conditions are given as follows:

$$
\begin{gathered}
u(r, 0)=0, \quad T(r, 0)=T_{a}, \quad \varphi(r, 0)=\varphi_{0} \\
\frac{\partial u}{\partial r}(0, \bar{t})=\frac{\partial T}{\partial r}(0, \bar{t})=\frac{\partial \varphi}{\partial r}(0, \bar{t})=0 \\
u(a, \bar{t})=0,-k_{f} \frac{\partial T}{\partial r}(a, \bar{t})=h\left(T(a, \bar{t})-T_{a}\right) \\
D_{B} \frac{\partial \varphi}{\partial r}(a, \bar{t})=-\frac{D_{T}}{T_{a}} \frac{\partial T}{\partial r}(a, \bar{t})
\end{gathered}
$$

where $h$ is the heat transfer coefficient, $k_{f}$ is nanofluid thermal conductivity coefficient and $\varphi_{0}$ is the nanoparticles initial concentration. We introduce the dimensionless variables and parameters as follows:

$$
\begin{aligned}
& \theta=\frac{T-T_{0}}{T_{a}-T_{0}}, W=\frac{u}{V}, \eta=\frac{r}{a}, t=\frac{\bar{t} v_{f}}{a^{2}}, \\
& v_{f}=\frac{\mu_{0}}{\rho_{f}}, \operatorname{Re}=\frac{V a}{v_{f}}, \bar{P}=\frac{a P}{\mu_{0} V}, N b=\frac{\tau D_{B} \varphi_{0}}{\alpha_{f}}, \\
& G=-\frac{\partial \bar{P}}{\partial Z}, Z=\frac{z}{a}, \operatorname{Pr}=\frac{\mu_{0} c_{P f}}{k_{f}}, B i=\frac{h a}{k_{f}}, \\
& E c=\frac{V^{2}}{c_{P f}\left(T_{a}-T_{0}\right)}, H=\frac{\varphi}{\varphi_{0}}, N t=\frac{\tau D_{T}\left(T_{a}-T_{0}\right)}{T_{a} \alpha_{f}}, \\
& \tau=\frac{\left(\rho c_{p}\right)_{s}}{\left(\rho c_{p}\right)_{f}}, \beta=m\left(T_{a}-T_{0}\right), S c=\frac{v_{f}}{D_{B}} .
\end{aligned}
$$

The dimensionless governing equations together with the appropriate initial and boundary conditions can be written as:

$$
\begin{gathered}
\frac{\partial W}{\partial t}+\operatorname{Re} \frac{\partial W}{\partial \eta}=G+e^{-\beta \theta}\left(\frac{\partial^{2} W}{\partial \eta^{2}}+\frac{1}{\eta} \frac{\partial W}{\partial \eta}-\beta \frac{\partial W}{\partial \eta} \frac{\partial \theta}{\partial \eta}\right) \\
\operatorname{Pr} \frac{\partial \theta}{\partial t}+\operatorname{Pr} \operatorname{Re} \frac{\partial \theta}{\partial \eta}=\frac{1}{\eta} \frac{\partial}{\partial \eta}\left(\eta \frac{\partial \theta}{\partial \eta}\right) \\
+\left\{N b \frac{\partial \theta}{\partial \eta} \frac{\partial H}{\partial \eta}+N t\left(\frac{\partial \theta}{\partial \eta}\right)^{2}\right\}+E c \operatorname{Pr} e^{-\beta \theta}\left(\frac{\partial W}{\partial \eta}\right)^{2} \\
S c \frac{\partial H}{\partial t}+S c \operatorname{Re} \frac{\partial H}{\partial \eta}=\frac{1}{\eta} \frac{\partial}{\partial \eta}\left(\eta \frac{\partial H}{\partial \eta}\right)+\frac{N t}{N b} \frac{\partial^{2} \theta}{\partial \eta^{2}}
\end{gathered}
$$

with initial and boundary conditions:

$$
\begin{aligned}
& W(\eta, 0)=0, \quad \theta(\eta, 0)=0, \quad H(\eta, 0)=1 \\
& \frac{\partial W}{\partial \eta}(0, t)=\frac{\partial \theta}{\partial \eta}(0, t)=\frac{\partial H}{\partial \eta}(0, t)=0 \\
& W(1, t)=0, \quad \frac{\partial \theta}{\partial \eta}(1, t)=-B i(\theta(1, t)-1) \\
& \frac{\partial H}{\partial \eta}(1, t)=-\frac{N t}{N b} \frac{\partial \theta}{\partial \eta}(1, t)
\end{aligned}
$$

where $R e$ is Reynolds number such that $R e>0$ represents suction, $R e<0$ represents injection, and $R e=0$ corresponds to the case of impermeable pipe wall, $N b$ is the Brownian motion parameter, $N t$ is the thermophoresis parameter, $B i$ is the Biot number, $\beta$ is the variable viscosity parameter, $S c$ is the Schmidt number, $P r$ is the Prandtl number, $E c$ is the Eckert number and $G$ is the pressure gradient parameter. The quantities of practical interest in this study are the skin friction coefficient $C_{f}$ and the local Nusselt number $N u$ which are defined as;

$$
C_{f}=\frac{a \tau_{w}}{\mu_{0} V}, \quad N u=\frac{a q_{w}}{k_{f}\left(T_{a}-T_{0}\right)}
$$

where $\tau_{w}$ is the wall shear stress and $q_{w}$ is the heat flux at the pipe wall given by;

$$
\tau_{w}=\left.\mu_{f} \frac{\partial u}{\partial r}\right|_{r=a}, q_{w}=-\left.k_{f} \frac{\partial T}{\partial r}\right|_{r=a}
$$

Substituting equations (17) into (16), we obtain

$$
\left.\begin{array}{c}
C_{f}=e^{-\beta \theta} \frac{\partial W}{\partial \eta}, \\
N u=-\frac{\partial \theta}{\partial \eta},
\end{array}\right\} \text { at } \eta=1
$$

\section{Numerical Procedure}

Equations (10)-(15) constitute a system of nonlinear initial boundary value problem (IBVP) and are solved numerically using a semi-discretization finite difference method known as method of lines [21]. Spatial interval $0 \leq \eta \leq 1$ is partitioned into $N$ equal parts with grid size $\Delta \eta=1 / N$ and grid points $\eta_{i}=(i-1) \Delta \eta, 1 \leq i \leq N+1$. The first and second spatial derivatives in equations (10)-(12) are approximated with second-order central finite differences. Let $W_{i}(t), \theta_{i}(t)$ and $H_{i}(t)$ be approximation of $W\left(\eta_{i}, t\right), \theta\left(\eta_{i}, t\right)$ and $H\left(\eta_{i}, t\right)$, then the semi-discrete system for the problem becomes

$$
\begin{aligned}
\frac{d W_{i}}{d t} & =G-\operatorname{Re} \frac{\left(W_{i+1}-W_{i-1}\right)}{2 \Delta \eta}+e^{-\beta \theta_{i}} \frac{\left(W_{i+1}-2 W_{i}+W_{i-1}\right)}{(\Delta \eta)^{2}} \\
+e^{-\beta \theta_{i}} \frac{\left(W_{i+1}-W_{i-1}\right)}{2 \eta_{i} \Delta \eta}-\beta e^{-\beta \theta_{i}} \frac{\left(\theta_{i+1}-\theta_{i-1}\right)\left(W_{i+1}-W_{i-1}\right)}{4(\Delta \eta)^{2}} & \operatorname{Pr} \frac{d \theta_{i}}{d t}=-\operatorname{Pr} \operatorname{Re}\left(\frac{\theta_{i+1}-\theta_{i-1}}{2 \Delta \eta}\right)+\frac{\left(\theta_{i+1}-2 \theta_{i}+\theta_{i-1}\right)}{(\Delta \eta)^{2}} \\
+ & \frac{\theta_{i+1}-\theta_{i-1}}{2 \eta_{i} \Delta \eta}+N b \frac{\left(\theta_{i+1}-\theta_{i-1}\right)\left(H_{i+1}-H_{i-1}\right)}{4(\Delta \eta)^{2}} \\
+ & N t\left(\frac{\theta_{i+1}-\theta_{i-1}}{2 \Delta \eta}\right)^{2}+E c \operatorname{Pr} e^{-\beta \theta}\left(\frac{W_{i+1}-W_{i-1}}{2 \Delta \eta}\right)^{2} \\
S c \frac{d H_{i}}{d t} & =-S c \operatorname{Re} \frac{\left(H_{i+1}-H_{i-1}\right)}{2 \Delta \eta}+\frac{\left(H_{i+1}-2 H_{i}+H_{i-1}\right)}{(\Delta \eta)^{2}} \\
& +\frac{\left(H_{i+1}-H_{i-1}\right)}{2 \eta_{i} \Delta \eta}+\frac{N t}{N b} \frac{\left(\theta_{i+1}-2 \theta_{i}+\theta_{i-1}\right)}{(\Delta \eta)^{2}}
\end{aligned}
$$


with initial conditions

$$
W_{i}(0)=\theta_{i}(0)=0, H_{i}(0)=1, \quad 1 \leq i \leq N+1
$$

The equations corresponding to the first and last grid points are modified to incorporate the boundary conditions as follows;

$$
\begin{aligned}
& W_{2}=W_{1}, \theta_{2}=\theta_{1}, H_{2}=H_{1}, W_{N+1}=0, \\
& \theta_{N+1}=\theta_{N}(1-B i \Delta \eta)+B i \Delta \eta, \\
& H_{N+1}=H_{N}-N t \frac{\left(\theta_{N+1}-\theta_{N}\right)}{N b}
\end{aligned}
$$

Equations (19)-(23) is a system of initial value nonlinear ordinary differential equations and can be easily solved iteratively using Runge-Kutta Fehlberg integration technique [21] implemented on a computer using MATLAB. From the process of numerical computation, the skin-friction coefficient and the Nusselt number in equation (18) are also worked out and their numerical values are presented.

\section{Results and Discussion}

The combined effects of temperature dependent viscosity, Brownian motion, thermophoresis and convective cooling on unsteady flow of nanofluids in a pipe with permeable wall are investigated. The semi-discretization approach is used to solve the governing non-linear partial different equation numerically. The numerical solution for the representative velocity profiles, temperature profiles, nanoparticles concentration profiles, skin friction and Nusselt number have been carried out by assigning some arbitrary chosen specific values to various parameters controlling the flow system. The results are presented in Figures 2 - 26. The Prandtl number (Pr) is taken 6.2 which is within the range from $6.2 \leq \operatorname{Pr} \leq 7.1$ the most encountered fluids in nature and frequently used in engineering and industries [15-17]. Table 1 illustrates the effects of different parameters governing the flow on skin friction and Nusselt number coefficients.

\subsection{Non-Dimensional Velocity Profiles with Parameter Variations}

The effects of parameter variation on velocity profiles are displayed in Figures 2-8. In Figure $2 a$ and Figure $2 b$, it is observed that the nanofluid velocity is high at the centerline region of the pipe and is decreasing towards the pipe wall. Moreover, the velocity reaches steady state quickly when the fluid is injected in to the pipe $(R e<0)$ compared with suction $(\operatorname{Re}>0)$. The velocity at the center of the pipe increases with increasing time and reaches its minimum value towards the pipe surface satisfying the prescribed initial and boundary conditions as demonstrated in Figure 3. Figure 4 illustrates the variation of nanofluid velocity with variable viscosity parameter. It is noted that the nanofluid moves faster with increasing variable viscosity parameter in the presence of suction. This is due to the fact that increasing $\beta$ result in decreasing the viscosity of the nanofluids. Similar trend are observed with growing Eckert number and pressure gradient parameter as illustrated in Figure 5 and Figure 6, respectively. The opposite behavior is observed with increasing the Biot number as seen in Figure 7. Increasing Biot number leads to reduce the nanofluid velocity. This is because an increase in Biot number raises convective cooling due to heat loss to the ambient from the pipe surface and hence reduces the nanofluid velocity. The increases of nanofluid velocity with increasing suction and decreasing with increasing injection is observed from Figure 8.

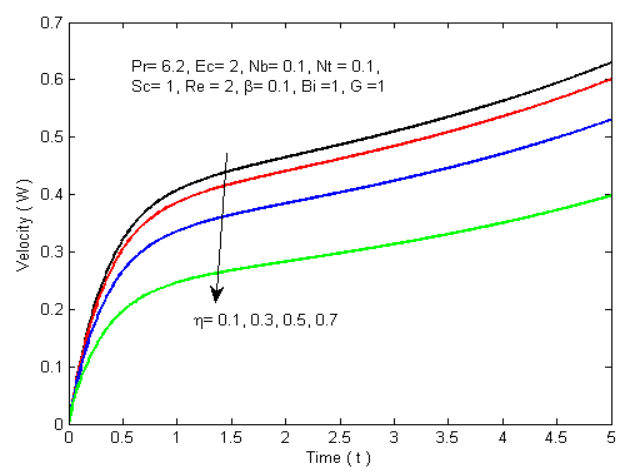

Figure 2a. Velocity profiles with increasing distance

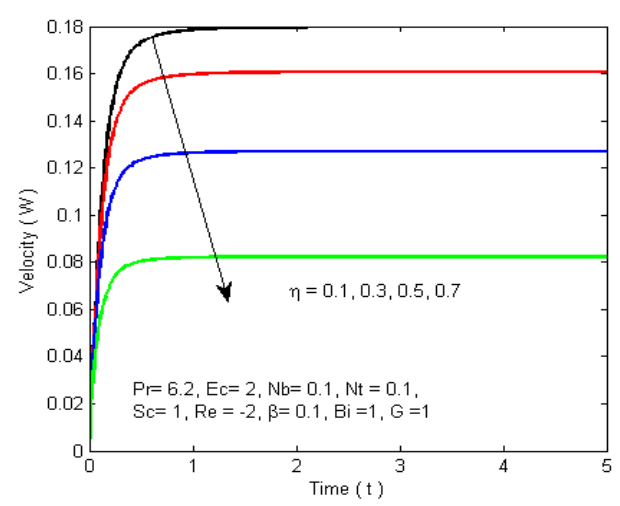

Figure $2 \boldsymbol{b}$. Velocity profiles with increasing distance

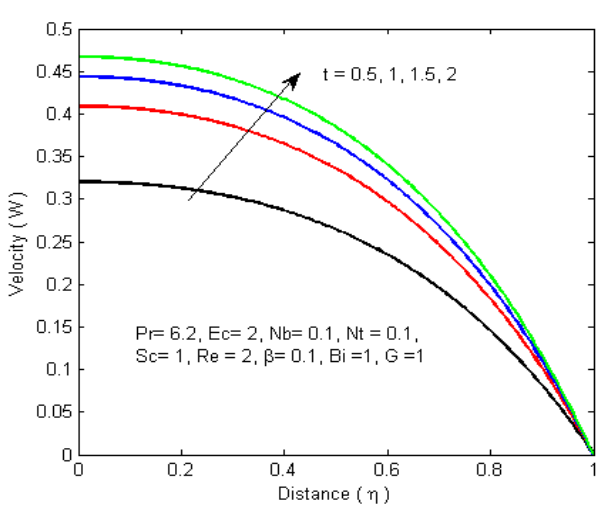

Figure 3. Velocity profiles with increasing time 


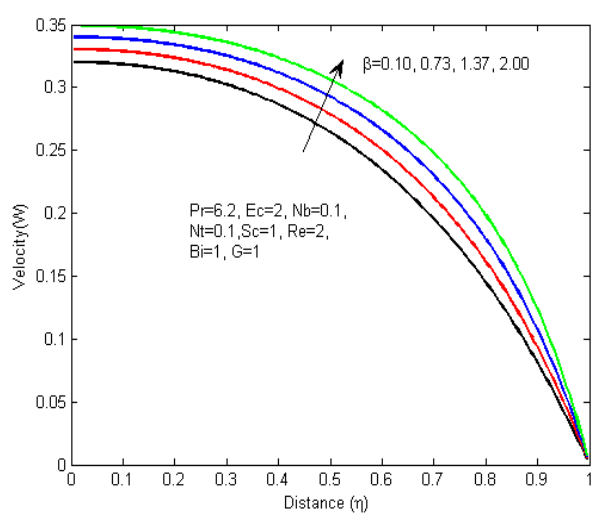

Figure 4. Velocity profiles with increasing $\beta$

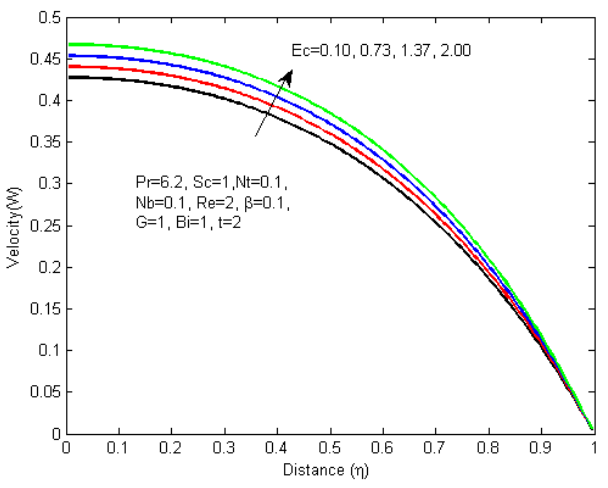

Figure 5. Velocity profiles with increasing Ec

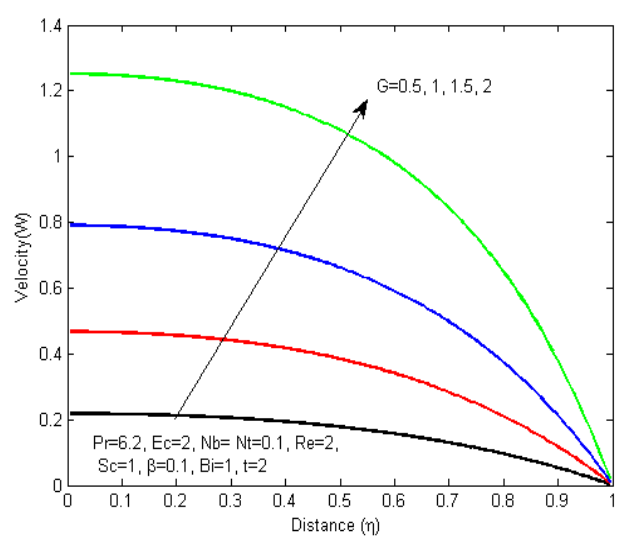

Figure 6. Velocity profiles with increasing $G$

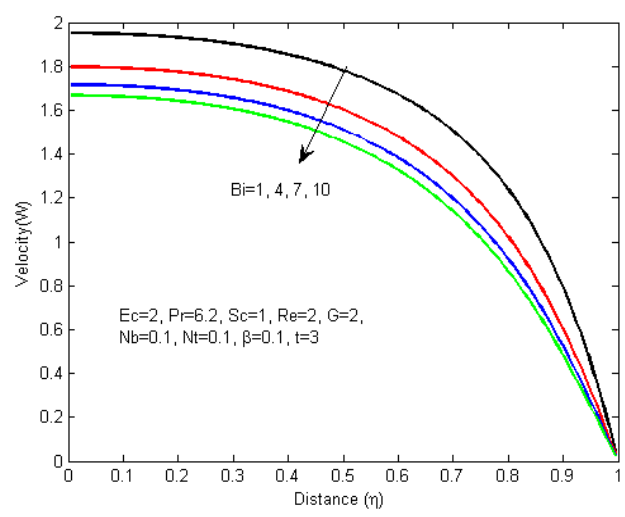

Figure 7. Velocity profiles with increasing $B i$

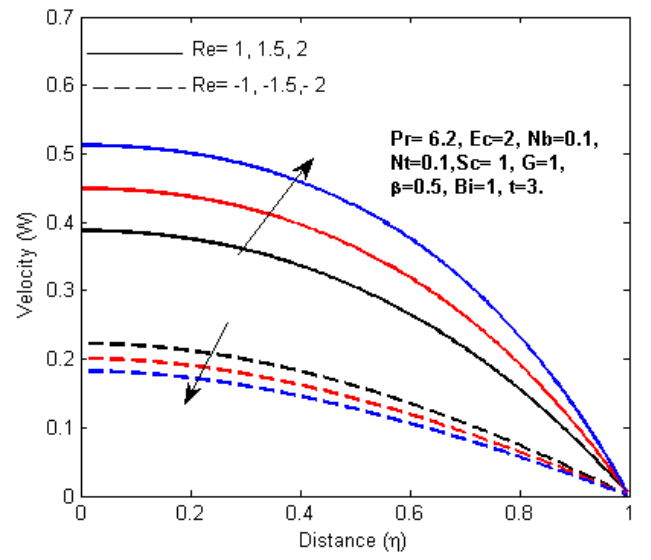

Figure 8. Velocity profiles with increasing suction and injection

\subsection{Non- Dimensional Temperature Profiles with Parameter Variations}

Figures 9-14 demonstrate the nanofluids temperature profiles across the pipe and the effect of different parameters in the fluid flow system. Generally, due to convective heat loss to ambient surrounding following the Newton's law of cooling, the nanofluid temperature near the pipe wall is shown decreasing. In Figure $9 \mathrm{a}$ and Figure $9 \mathrm{~b}$, it is observed that the nanofluid temperature is higher at the pipe wall. However, the temperature reaches its steady state earlier when the external fluid added in to the pipe fluid (injection) as seen in Figure 9b. An increase of the nanofluid temperature is observed with increasing time and Eckert number as shown in Figures 10 and 11. This may be attributed to the fact that, as $E c$ increases the internal heat generation within the fluid due velocity gradient increases, leading to a rise in temperature. It is noted that the nanofluid temperature is decreasing at the centre of the pipe before the flow reversal near the pipe wall with increasing variable viscosity parameter as shown in Figure 12 . The nanofluid temperature is increasing at the centreline region followed by flow reversal towards the pipe wall with increasing Biot as illustrated in Figure 13. This can be explained as, increasing Biot number indicates a rise in convective cooling due to heat loss to the ambient surrounding from the pipe surface and hence the temperature at that wall of pipe lead to the overall cooling of the bulk nanofluid. Figure 14 elucidates the temperature profiles variation with increasing injection and suction. It is observed that the nanofluid temperature decreases with increasing both suction and injection. 


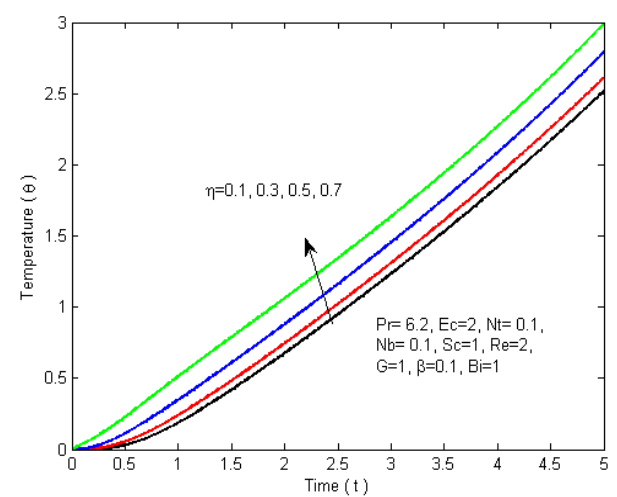

Figure 9a. Temperature profiles with increasing distance

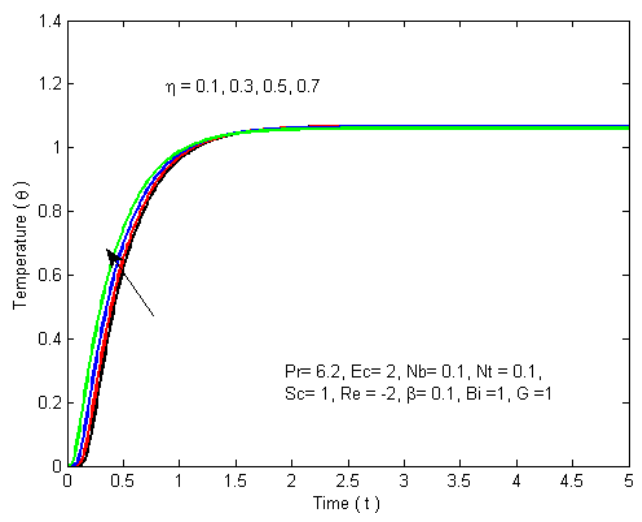

Figure 9b. Temperature profiles with increasing distance

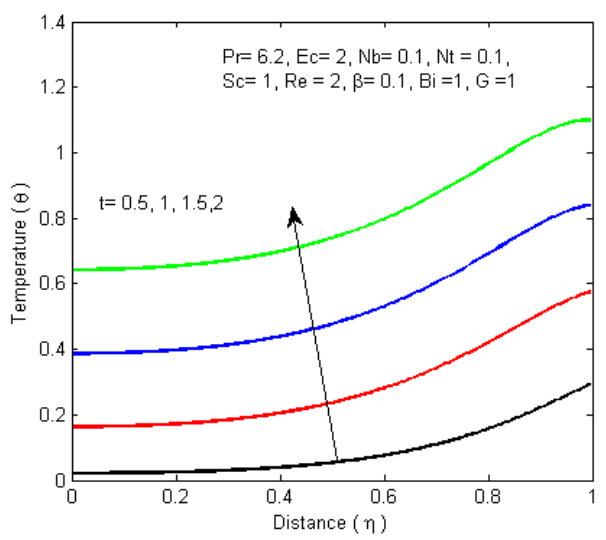

Figure 10. Temperature profiles with increasing Time

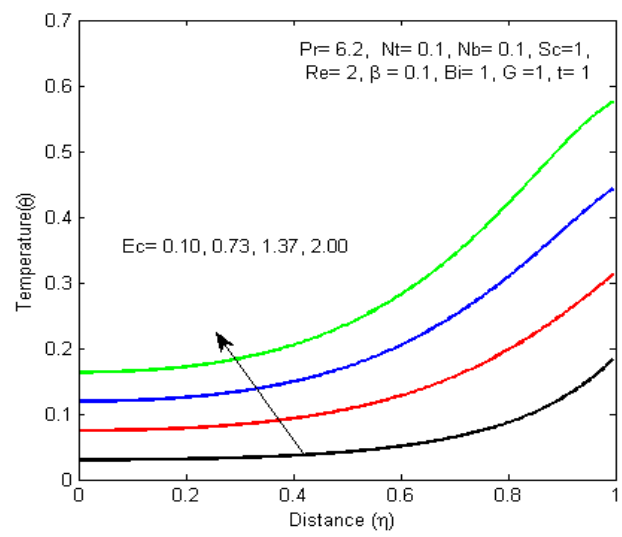

Figure 11. Temperature profiles with increasing Ec

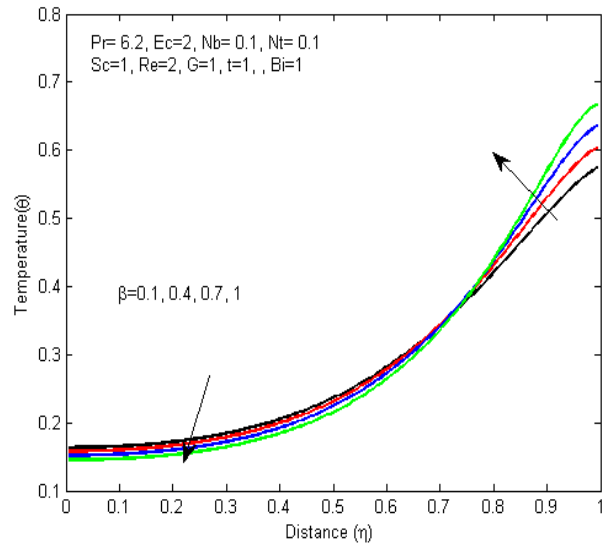

Figure 12. Temperature profiles with increasing $\beta$

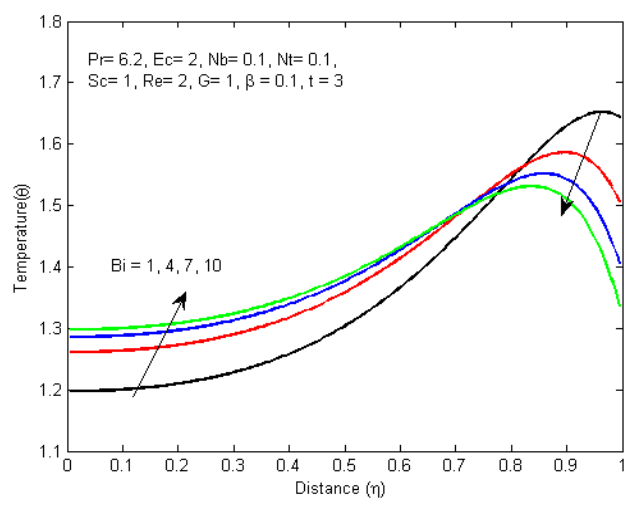

Figure 13. Temperature profiles with increasing $B i$

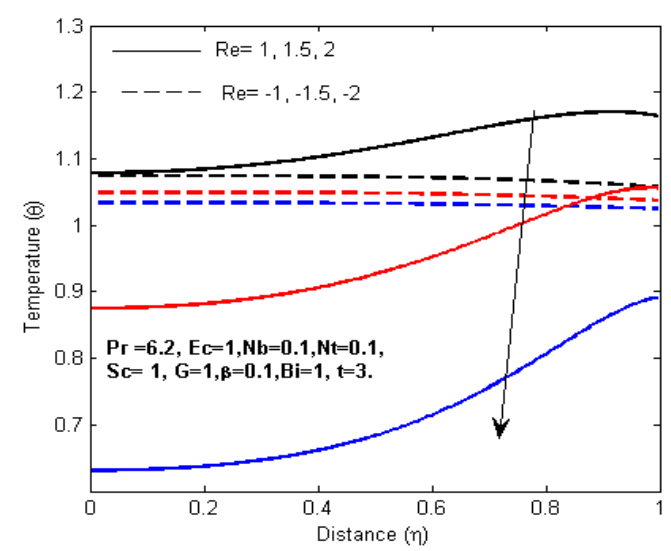

Figure 14. Temperature profiles with increasing suction and injection

\subsection{Non-Dimensional Nanoparticles Volume Concentration Profiles with Parameter Variations}

Figures 15-22 demonstrate the effects of various physical parameters which determine the flow on the nanoparticles concentration profiles. Figure 15 shows the effect of increasing distance to nanoparticles concentration. It is noted that at the first time, the nanoparticles volume fraction is high at the pipe wall for a very short time, and then become higher at the center of the pipe as time increases. In Figure 16, it is observed that the nanoparticles volume fraction increases with increasing time. In addition, the 
nanoparticles concentration at the center of the pipe is higher compared at the pipe surface. A combined increase in the viscosity, viscous dissipation and thermophoresis shown in Figures 17-19 causes an increase in the nanoparticles concentration at the centreline region of the pipe and reverse towards the pipe wall. This could be explained as due to variation of kinetic energy of nanoparticles and mixtures of mobile particles in the fluid where the different particle exhibit different responses to the force of a temperature gradient. The opposite results is noted from Figure 20; with increasing the motion of particles $(\mathrm{Nb})$, the nanoparticles concentration is decreasing at the centre of the pipe and more concentrated near the pipe wall. In Figure 21, the increase of nanoparticles concentration with Biot is observed. The nanoparticles volume fraction become more concentrated with increasing suction compared with increasing injection as illustrated in Figure 22.

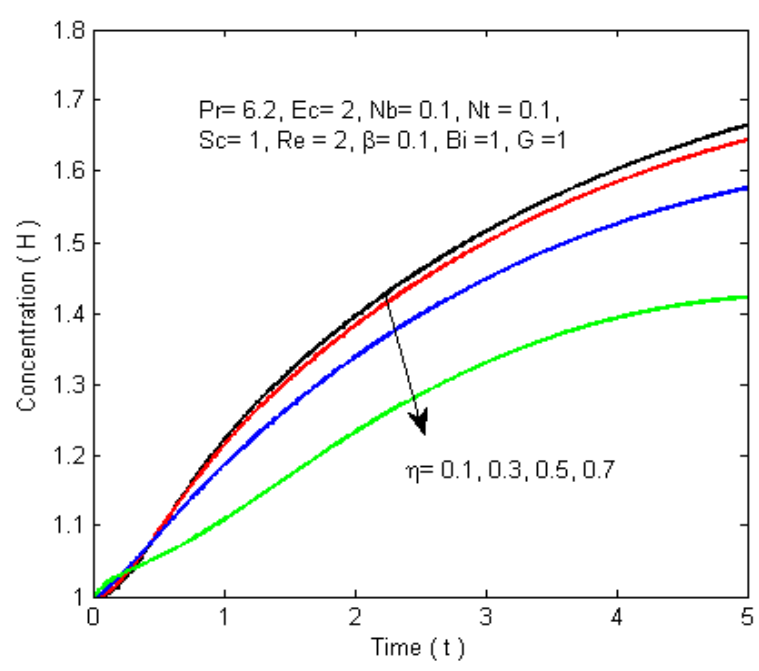

Figure 15. Nanoparticles distribution profiles with increasing distance

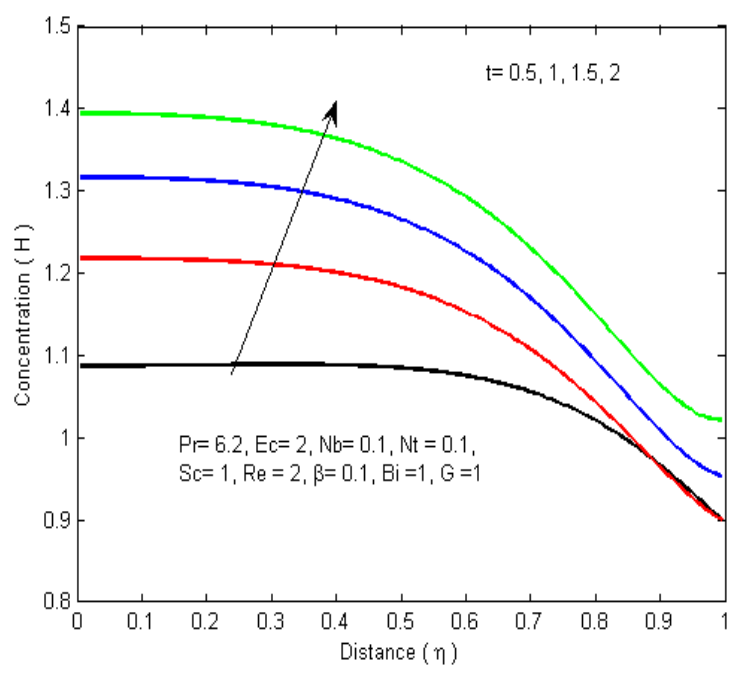

Figure 16. Nanoparticles distribution profiles with increasing time.

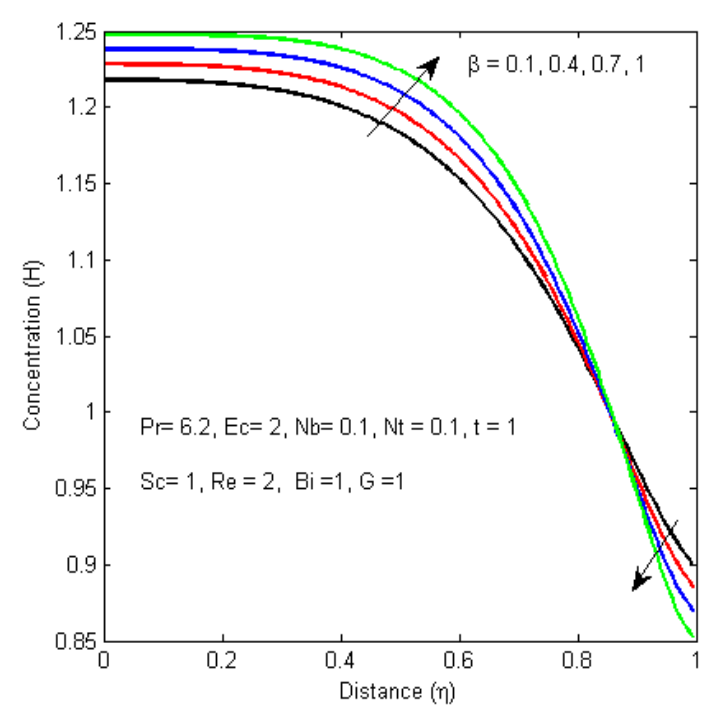

Figure 17. Nanoparticles distribution profiles with increasing $\beta$

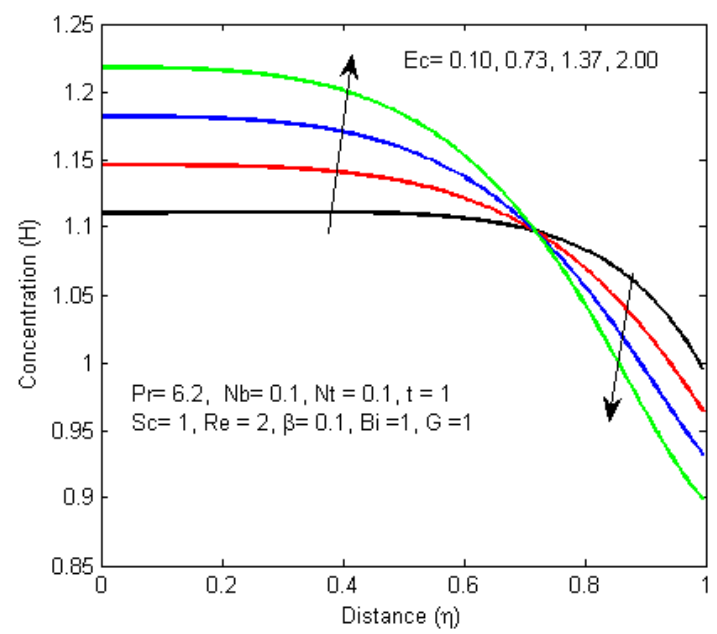

Figure 18. Nanoparticles distribution profiles with increasing Ec

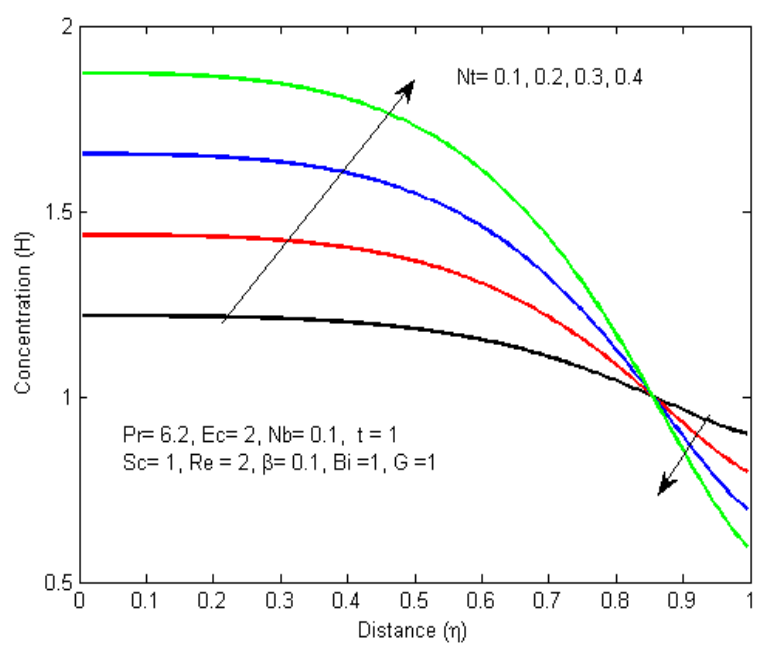

Figure 19. Nanoparticles distribution profiles with increasing Nt 


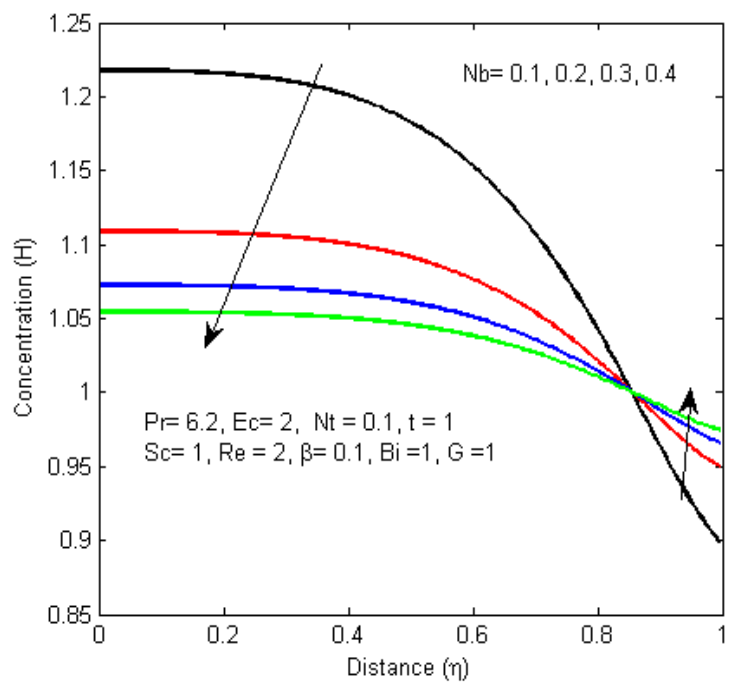

Figure 20. Nanoparticles distribution profiles with increasing $\mathrm{Nb}$

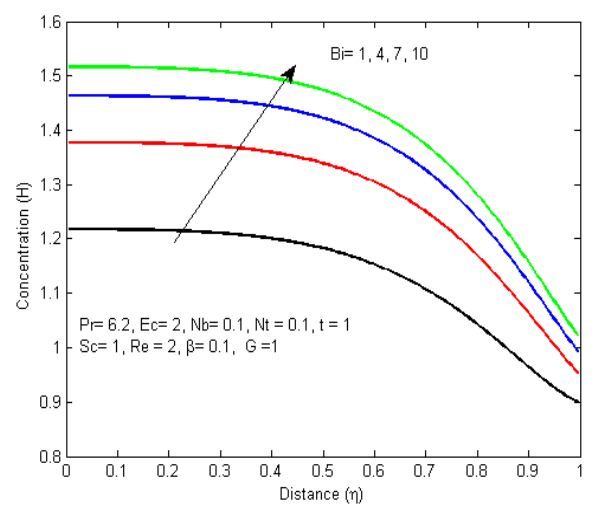

Figure 21. Nanoparticles distribution profiles with increasing Bi

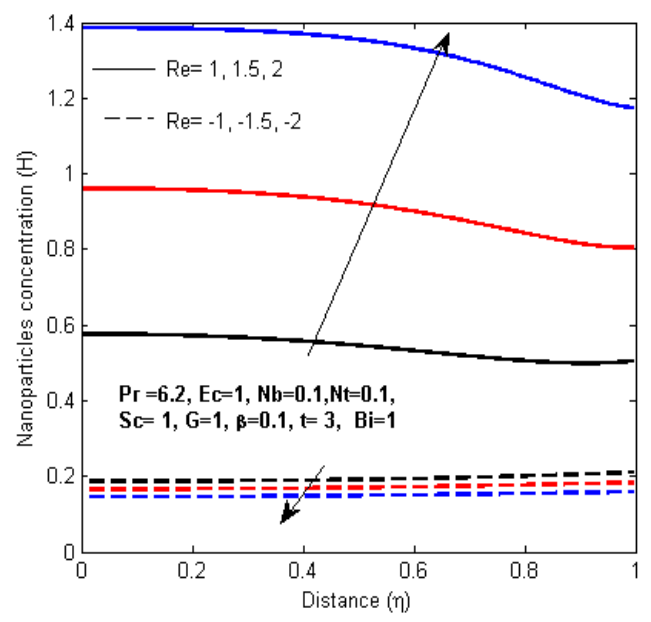

Figure 22. Nanoparticles distribution profiles with increasing Re.

\subsection{Skin Friction and Local Nusselt Number with Parameters Variation}

Figures 23-26 together with Table 1 demonstrate the variations of skin friction and Nusselt number with different parameters. In general, Biot number, Eckert number, variable viscosity parameter, pressure gradient parameter and Reynolds number have high effects on skin friction and Nusselt number coefficients while Brownian motion and thermophoresis parameters have less effect. By keeping fixed values of parameters, both Nusselt number and skin friction varies with time. It is observed that the friction between the pipe surface and nanofluid relative to motion is increasing negatively with increasing, Eckert number, Biot number, and pressure gradient for $t=3$, as shown in Table 1 . The opposite observation is seen with Nusselt number. The convective to conductive heat transfer $(\mathrm{Nu})$ at the pipe surface is increasing with Eckert number, Biot number, and pressure gradient. Figures 23-26 supplement the information obtained from Table 1 for the time interval $[0,5]$. The friction between the pipe wall and the fluid is decreasing with increasing Ec and $\beta$ for some range of time and then reverse the behavior as shown in Figure 23. Figure 24 points out that growth in suction $(\mathrm{R}>0)$ magnifies the skin friction while a growth in injection $(\mathrm{R}<0)$ reduces the skin friction. Figure 25 elucidates the rate of heat transfer at the pipe wall with increasing Ec and $\beta$. The heat transfer rate $(N u)$ is high with increasing both Ec and $B$. The heat transfer rate is increasing with increasing suction and decreasing with increasing injection this is illustrated in Figure 26.

Table 1. Computation showing the skin friction and Nusselt number Pr= $6.2, S c=1$.

\begin{tabular}{|c|c|c|c|c|c|c|c|c|c|}
\hline$t$ & $B i$ & $\beta$ & $E c$ & $N t$ & $\mathrm{Nb}$ & $R e$ & $\boldsymbol{G}$ & $C_{f}$ & $N u$ \\
\hline 1 & 1 & 0.1 & 1 & 0.1 & 0.1 & 2 & 1 & -1.0512 & -0.6306 \\
\hline 3 & 1 & 0.1 & 1 & 0.1 & 0.1 & 2 & 1 & -1.1570 & -0.1067 \\
\hline 5 & 1 & 0.1 & 1 & 0.1 & 0.1 & 2 & 1 & -1.2245 & 0.4242 \\
\hline 3 & 5 & 0.1 & 1 & 0.1 & 0.1 & 2 & 1 & -1.1742 & 0.1207 \\
\hline 3 & 10 & 0.1 & 1 & 0.1 & 0.1 & 2 & 1 & -1.1816 & 0.4510 \\
\hline 3 & 1 & 0.4 & 1 & 0.1 & 0.1 & 2 & 1 & -1.4389 & 0.1209 \\
\hline 3 & 1 & 0.8 & 1 & 0.1 & 0.1 & 2 & 1 & -2.0621 & 0.7045 \\
\hline 3 & 1 & 0.1 & 2 & 0.1 & 0.1 & 2 & 1 & -1.2184 & 0.6491 \\
\hline 3 & 1 & 0.1 & 3 & 0.1 & 0.1 & 2 & 1 & -1.2902 & 1.5260 \\
\hline 3 & 1 & 0.1 & 1 & 0.2 & 0.1 & 2 & 1 & -1.1570 & -0.1058 \\
\hline 3 & 1 & 0.1 & 1 & 0.4 & 0.1 & 2 & 1 & -1.1572 & -0.1040 \\
\hline 3 & 1 & 0.1 & 1 & 0.1 & 0.2 & 2 & 1 & -1.1570 & -0.1067 \\
\hline 3 & 1 & 0.1 & 1 & 0.1 & 0.4 & 2 & 1 & -1.1570 & -0.1067 \\
\hline 3 & 1 & 0.1 & 1 & 0.1 & 0.1 & -2 & 1 & -0.2695 & 0.0248 \\
\hline 3 & 1 & 0.1 & 1 & 0.1 & 0.1 & 0 & 1 & -0.4982 & 0.1351 \\
\hline 3 & 1 & 0.1 & 1 & 0.1 & 0.1 & 2 & 1.5 & -1.8530 & 0.8558 \\
\hline 3 & 1 & 0.1 & 1 & 0.1 & 0.1 & 2 & 2 & -2.7467 & 2.5565 \\
\hline
\end{tabular}




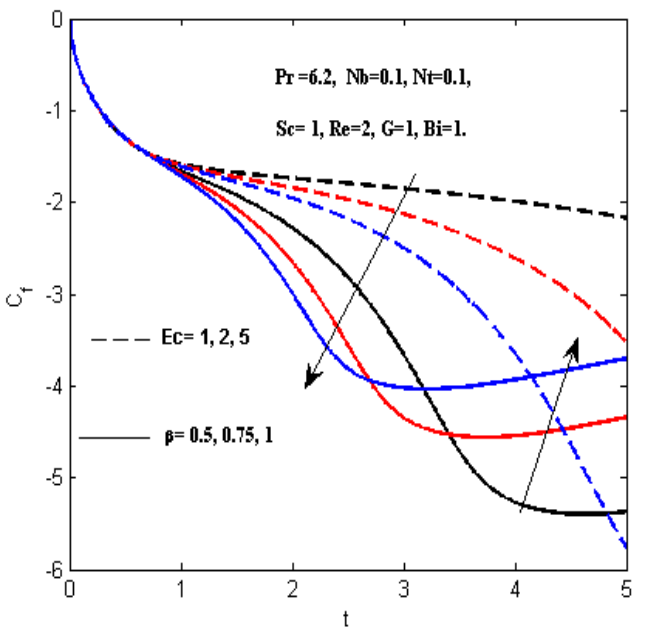

Figure 23. Skin friction with increasing Ec and $\beta$

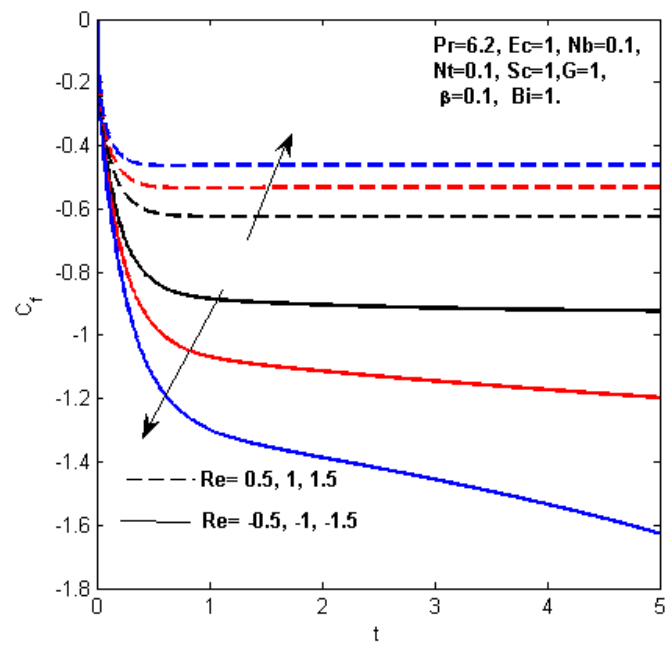

Figure 24. Skin friction with increasing suction and injection

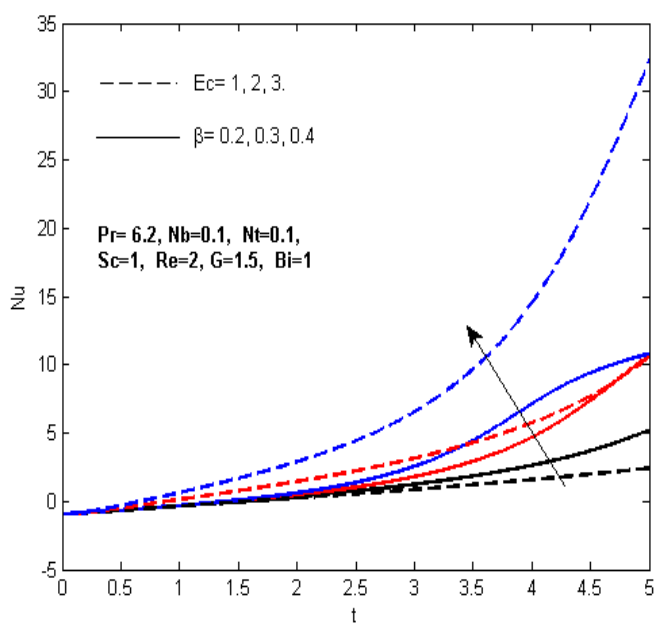

Figure 25. Nusselt number with increasing $\beta$ and $E c$

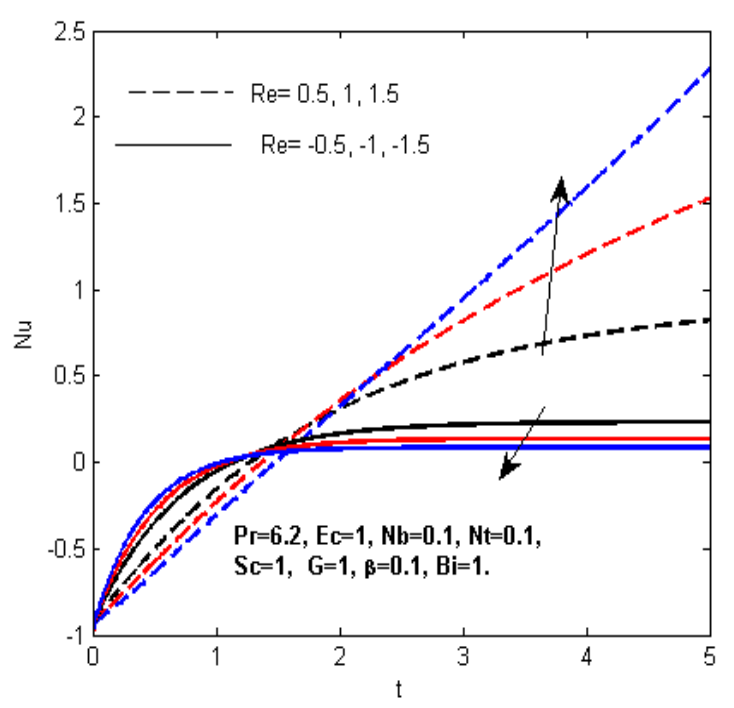

Figure 26. Nusselt number with increasing suction and injection

\section{Conclusions}

In this paper, the combined effects of temperature dependent viscosity, Brownian motion, thermophoresis and convective cooling on unsteady flow of nanofluids in a pipe with permeable wall are investigated. The coupled nonlinear governing equations were derived, non-dimensionalised and numerically solved using a semi-discretization finite difference method coupled with a Runge-Kutta Fehlberg integration scheme. Based on the graphical representations, the following main conclusions are drawn:

- The nanofluid velocity and temperature reaches its steady state quickly with injection $(R e<0)$ compared with suction $(R e>0)$.

- The nanofluid moves faster with increasing variable viscosity parameter, Eckert number, pressure gradient and suction and reducing with increasing Biot number and injection.

- The nanofluid temperature is increasing near the pipe wall with increasing Eckert number and variable viscosity parameter and reduced due to convective heat loss to ambient following the Newton's law of cooling. The nanofluid temperature decreases with increasing both suction and injection.

- The nanoparticles volume fraction is increasing at the centreline region with increasing Biot number, viscosity parameter, Eckert number, and thermophoresis while decreasing with Brownian motion.

- $\quad$ Skin friction and Nusselt number coefficients are more affected with Biot number, Eckert number, variable viscosity parameter, pressure gradient parameter and Reynolds number while Brownian motion and thermophoresis parameters have less effect.

- $\quad$ Skin friction and Nusselt number are increasing with increasing suction $(\mathrm{R}>0)$ and decreasing with increasing injection $(\mathrm{R}<0)$. 


\section{References}

[1] Karode, S. K., (2001), Laminar flow in channels with porous walls, J. Membr. Sci., 191, pp. 237-241.

[2] Oxarango, L., Schmitz,. P., Quintard, M., (2004), Laminar flow in channels with wall suction or injection: a new model to study multi-channel filtration systems, Chem. Eng. Sci., 59, pp. 1039-1051.

[3] Moussy, Y., Snider, A. D., (2009), Laminar flow over pipes with injection and suction through the porous wall at low Reynolds number, J. Membr. Sci., 327, pp. 104-107.

[4] Erdoğan , M. E., Imrak, C. E.,(2008), On the flow in a uniformly porous pipe, Int. J. Non-Linear Mech., 43, pp. 292-301.

[5] Tsangaris, S. Kondaxakis, D., Vlachakis, N.W., (2007), Exact solution for flow in a porous pipe with unsteady wall suction and/or injection, Comm. Nonlinear Sci. Num. Simul., 12, pp. 1181-1189.

[6] Mutuku-Njane, W. N., Makinde, O. D., (2014), Hydromagnetic bioconvection of nanofluid over a permeable vertical plate due to gyrotactic microorganisms, Comp. Fluids, 95, pp. 88-97.

[7] Theuri, D., Makinde, O. D., (2014), Thermodynamic analysis of variable viscosity MHD unsteady generalized Couette flow with permeable walls, Appl. Computational Math., 3, 1-8.

[8] Kaufui, V. W., Omar, D. L.(2003), Applications of nanofluids: current and future, Adv. Mech. Eng., 11 pp.

[9] Xuan, Y. Li, Q., (2003), Investigation on convective heat transfer and flow features of nanofluids, J. Heat Transf., 125, pp. 151-155.

[10] Buongiorno, J., (2006), Convective transport in nanofluids, J. Heat Transfer., 128, pp. 240-250.

[11] Mutuku-Njane, W. N., Makinde, O. D., (2014), MHD nanofluid flow over a permeable vertical plate with convective heating, J. Compl Theor. Nanoscience, 3, pp. 667-675.
[12] Olanrewaju, M., Makinde,. O. D., (2013) On boundary layer stagnation point flow of a nanofluid over a permeable flat surface with Newtonian heating, Chem. Eng. Comm., pp. 200 836-852.

[13] Makinde, O. D., (2013), Effects of viscous dissipation and Newtonian heating on boundary layer flow of nanofluids over a flat plate, Int. J. Num. Meth. Heat and Fluid flow 23, pp. 1291-1303.

[14] Makinde, O. D., Khamis, S. A., Tshehla, M. S., Franks, O. (2014), Analysis of Heat Transfer in Berman Flow of Nanofluids with Navier Slip, Viscous Dissipation, and Convective Cooling, Adv. Math. Phys., 2014, 13 pages.

[15] Makinde, O. D., (2013), Computational modelling of nanofluids flow over a convectively heated unsteady stretching sheet, Curr. Nanoscience, 9, pp. 673-678.

[16] Oztop, H. F., Abu-Nada, E., (2008), Numerical study of natural convection in partially heated rectangular enclosures filled with nanofluids, Int. J. Heat Fluid Flow. 29, pp. $1326-1336$

[17] Kakac, S., Pramuanjaroenkij, A., (2009), Review of convective heat transfer enhancement with nanofluids, Int. J. Heat Mass Transf., 52, pp. 3187-3196.

[18] Makinde, O. D., (2009), Hermite-Pade approach to thermal radiation effect on inherent irreversibility in a variable viscosity channel flow, Comp. Math. Appl., 58, pp. 2330-2338.

[19] Kuppalapalle, V., Kerehalli, P. V., Chiu-on, NG., (2013), The effect of variable viscosity on the flow and heat transfer of a viscous $\mathrm{Ag}$-water and $\mathrm{Cu}$-water nanofluids, J. Hydro., 25, 8 pages.

[20] Makinde, O. D., (2012), Effects of variable viscosity on thermal boundary layer over a permeable flat plate with radiation and convective surface boundary condition. J. Mech Science Tech., 26, pp. 1615-1622.

[21] Na, T. Y. (1979), Computational methods in engineering boundary value problems, Academic press, New York.

[22] Klemp K., Herwig H., Selmann M.,(1990), Entrance flow in channel with temperature dependent viscosity including viscous dissipation effects. Proc. Third Int. Cong. Fluid Mech., Proc. Third Int. Cong. Fluid Mech., Cairo, Egypt, 3, p. 1257. 